\title{
溶融塩処理によるナノ光触媒薄膜の作製と高機能化
}

$\begin{array}{lllc}\text { 高 屋 駿 介1,* } & \text { 春 日翔多1,* } & \text { 関 } & \text { 蘇 軍 } 1, * \\ \text { 宮 澤 康 平1,* } & \text { 吉田浩 之 } & \text { 魯 } & \text { 云 }\end{array}$

1 千葉大学大学院工学研究科

2 千葉県産業支援技術研究所

J. Japan Inst. Met. Mater. Vol. 79, No. 9 (2015), pp. 429-433

(C) 2015 The Japan Institute of Metals and Materials

\section{Fabrication and Activity Enhancement of Nano-Photocatalyst Films by Molten Salt Treatment}

Shunsuke Takaya1,*, Shota Kasuga1,*, Sujun Guan ${ }^{1, *}$,

Kohei Miyazawa ${ }^{1, *}$, Hiroyuki Yoshida ${ }^{2}$ and Yun $\mathrm{Lu}^{1}$

${ }^{1}$ Graduate School \& Faculty of Engineering, Chiba University, Chiba 263-8522

${ }^{2}$ Chiba Industrial Technology Research Institute, Chiba 264-0017

Recently, potassium titanate, formed from titanium oxide with high photocatalytic activity has been attracted much attention. In the present work, Ti films on $\mathrm{Al}_{2} \mathrm{O}_{3}$ balls were fabricated by mechanical coating technique (MCT). To obtain potassium titanate, the Ti films on $\mathrm{Al}_{2} \mathrm{O}_{3}$ balls were oxidized in air and the subsequent molten salt treatment with $\mathrm{KNO}_{3}$ and $\mathrm{K}_{2} \mathrm{CO}_{3}$ mixture. After that, the films were oxidized in air again. The microstructure and composition of the samples were characterized by SEM, EDS, and XRD. The photocatalytic activity was evaluated by measuring the degradation rate of methylene blue (MB) solution. The results show that the amorphous potassium titanate with nano-lamellar was formed on the surface by oxidizing the Ti films and the subsequent molten salt treatment with $\mathrm{KNO}_{3}$ and $\mathrm{K}_{2} \mathrm{CO}_{3}$ mixture. 6-pottasium titanate $\left(\mathrm{K}_{2} \mathrm{Ti}_{6} \mathrm{O}_{13}\right)$ with nano-needle was obtained by oxidizing the amorphous potassium titanate with nano-lamellar in air. $\mathrm{K}_{2} \mathrm{Ti}_{6} \mathrm{O}_{13}$ with nano-needle showed high photocatalytic activity. [doi:10.2320/jinstmet.JAW201502]

(Received April 13, 2015; Accepted May 13, 2015; Published September 1, 2015)

Keywords: mechanical coating technique, molten salt treatment, nano-structure, potassium titanate, photocatalytic activity

\section{1. 緒言}

$\mathrm{TiO}_{2}$ 光触媒は紫外光照射により有害な有機物を分解・除 去でき，かつ化学的にもきわめて安定な環境浄化機能材料と して注目されて拈り，幅広い分野での応用が進められてい る1-7). $\mathrm{TiO}_{2}$ の派生体である層状構造を有するチタン酸ナト リウムやチタン酸カリウムなどのチタン酸化合物は, 光触媒 機能を有するという報告があり, 中でも 6 チタン酸カリウ ム $\left(\mathrm{K}_{2} \mathrm{Ti}_{6} \mathrm{O}_{13}\right)$ はユニークな物理化学特性やトンネル構造を含 む結晶構造で知られ, 高い光触媒機能を示すことも近年報告 されている8,9). チタン酸カリウムの作製手法としては, $\mathrm{KNO}_{3}$ および $\mathrm{K}_{2} \mathrm{CO}_{3}$ による溶融塩処理が挙げられる. 溶融 塩処理は金属の表面処理 ·熱処理に用いられている簡便かつ 安価な手法であり, その強力な酸化力および塩自体の熱分解 により分離した元素が金属表面にドープすることにより，金 属の表面特性を改質することができる。また， $\mathrm{TiO}_{2}$ を $\mathrm{KNO}_{3}$ による溶融塩処理することで, $\mathrm{K}$ や $\mathrm{N}$ などが金属表 面にドープすることによって，可視光化および光触媒機能の 向上が期待されている10-15)。これまでに簡便な金属の成膜

\footnotetext{
* 千葉大学大学院生 (Graduate Student, Chiba University)
}

法であるメカニカルコーティング法によりアルミナボール上 に成膜した Ti 薄膜に $\mathrm{KNO}_{3}$ の溶融塩処理を施すことで $\mathrm{TiO}_{2}$ に K のドープによる可視光応答型光触媒を作製でき た ${ }^{16)}$.

本研究ではメカニカルコーディング法によって作製した $\mathrm{Ti}$ 薄膜を大気酸化させて試料表面に $\mathrm{TiO}_{2}$ 薄膜を形成した後 に, $\mathrm{KNO}_{3}$ と $\mathrm{K}_{2} \mathrm{CO}_{3}$ を用いた混合溶融塩処理を施しアモル ファスのチタン酸カリウムを薄膜表面に生成させた。さら に, 溶融塩処理後に大気酸化させることにより紫外光照射に 対し, 高い光触媒機能を有するナノ $\mathrm{K}_{2} \mathrm{Ti}_{6} \mathrm{O}_{13}$ の光触媒薄膜 の作製を目的とした。 また作製した試料をXRD, SEM およ びEDSにて解析し, メチレンブルー水溶液を用いて光触媒 機能の評価を行うとともに光触媒機能へのナノ構造の寄与を 検討した.

\section{2. 実 験 方 法}

\section{1 ナノチタン酸カリウム薄膜の作製}

まず，簡便な金属の成膜法であるメカニカルコーティング 法17,18)を用いた。直径約 $1 \mathrm{~mm}$ のアルミナボール (HD, ニッ カトー侏) および純度 $99.1 \%$, 平均粒径 $30 \mu \mathrm{m}$ の $\mathrm{Ti}$ 粉末 (TMP-350, 大阪チタニウムテクノロジーズ物)をアルミナ 


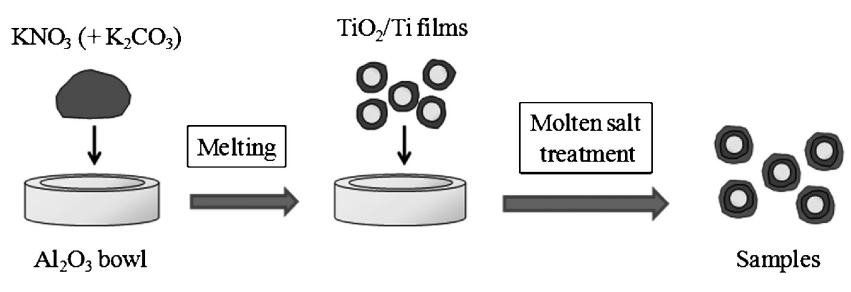

Fig. 1 Schematic diagram of the molten salt treatment.

製のポットに入れてから蓋をし，回転速度 $480 \mathrm{rpm}$ にて遊 星型ボールミル $(\mathrm{P}-6$, フリッチュ秼)でポットを $10 \mathrm{~h}$ 回転 させるメカニカルコーティング法によりアルミナボール表面 に Ti 薄膜を成膜させたものを供試体とした. この供試体に 電気炉にて $873 \mathrm{~K}, 973 \mathrm{~K}$ ，または $1073 \mathrm{~K} て ゙ ~ 2 \mathrm{~h}$ 大気酸化を 施し(それぞれ H-873, H-973，および H-1073 と表記）， $\mathrm{TiO}_{2}$ 薄膜を作製した。この $\mathrm{TiO}_{2}$ 薄膜を有する試料を溶融 した $\mathrm{KNO}_{3}(95$ mass $\%$ ) (純度 : $99.0 \%$, 和光純薬工業陎) と $\mathrm{K}_{2} \mathrm{CO}_{3}(5$ mass $\%$ ) (純度 : $99.5 \%$, 和光純薬工業侏)の中に 入れ, $773 \mathrm{~K} て ゙ ~ 20 \mathrm{~h}$ の混合溶融塩処理を行った(それぞれ K-873，K-973，および K-1073 と表記する). その後, K873, K-973，および K-1073 は電気炉にて $973 \mathrm{~K}$ で $20 \mathrm{~h}$ の 大気酸化を行う。このようにして作製した試料を $\mathrm{KH}-873$, KH-973，抢よび KH-1073 と表記する。これらの処理を Fig. 1 に図示する.

\section{2 解析方法と光触媒機能の評価}

作製した各試料について, $\mathrm{Cu}-\mathrm{K} \alpha$ 線を用いた XRD $(\mathrm{JDX}-$ 3530 , 日本電子侏) による結晶構造の解析, SEM (JSM$6510 \mathrm{~A}$, 日本電子(侏)による表面組織の観察抢よび EDS (JSM-6510A, 日本電子秼) による組成解析を行った. 光触 媒機能の評価は JIS R 1703-2 を参考にした. 底付円筒セル ( 840$)$ にボール状の試料を一層に敷き詰めて, あらかじめ暗 所にて吸着用メチレンブルー水溶液 $(20 \mu \mathrm{mol} / \mathrm{L}) 35 \mathrm{~mL}$ に $18 \mathrm{~h}$ 漬けて吸着させておく. その後, 試験用メチレンブ ルー水溶液 $(10 \mu \mathrm{mol} / \mathrm{L}) 35 \mathrm{~mL}$ に入れ替え, 照射強度 1.0 $\mathrm{mW} / \mathrm{cm}^{2}$ の紫外線を照射し， $20 \mathrm{~min}$ 抢きに $3 \mathrm{~h}$, メチレン ブルー水溶液の濃度を計測して光触媒機能を評価した.

\section{3. 実験結果および考察}

\section{1 溶融塩処理によって作製したチタン酸カリウム}

Fig. 2 に Ti 薄膜に大気酸化を施した $\mathrm{H}-873, \mathrm{H}-973$ ，お よび H-1073 の試料表面の SEM 像を示す. Ti 薄膜に大気 酸化を施す温度が高くなるほど, 試料表面にはルチルと思わ れる粒状の生成物 (同図(b))があり, 大気酸化温度が $1073 \mathrm{~K}$ では，それらは柱状 (同図 (c))に成長した。次に, Fig. 3 に それらの大気酸化を施した試料に対して混合溶融塩処理を施 した K-873, K-973 および K-1073の試料表面の SEM 像を 示す. 溶融塩処理を施すことで試料表面にナノ板状の生成物 が現れた。この生成物の厚みは約 $100 \mathrm{~nm}$ 以下であり, 試料 表面のほぼ全面に生成され, 大気酸化温度の違いによる生成 物の違いは見られなかった.
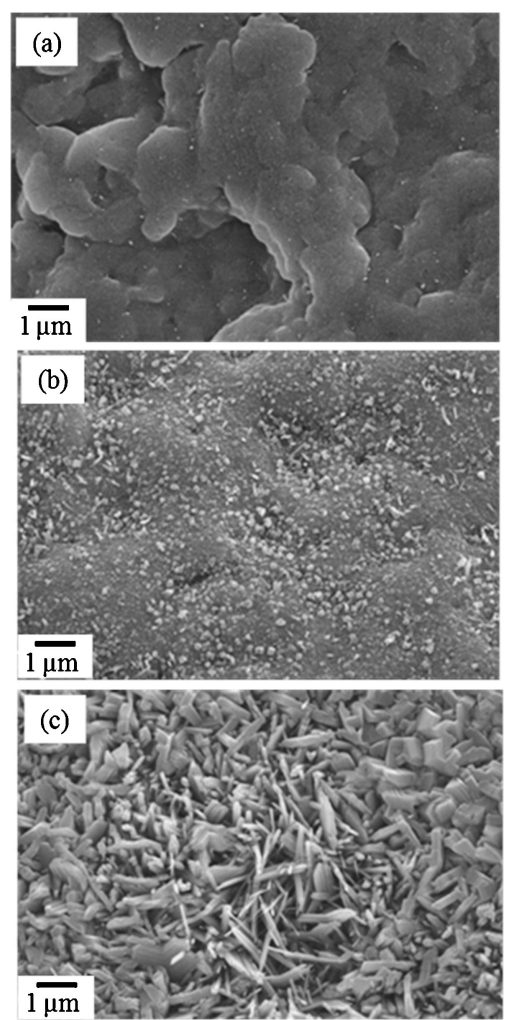

Fig. 2 SEM images of surfaces of $\mathrm{TiO}_{2}$ thin films for (a) H873, (b) H-973, and (c) $\mathrm{H}-1073$ samples.
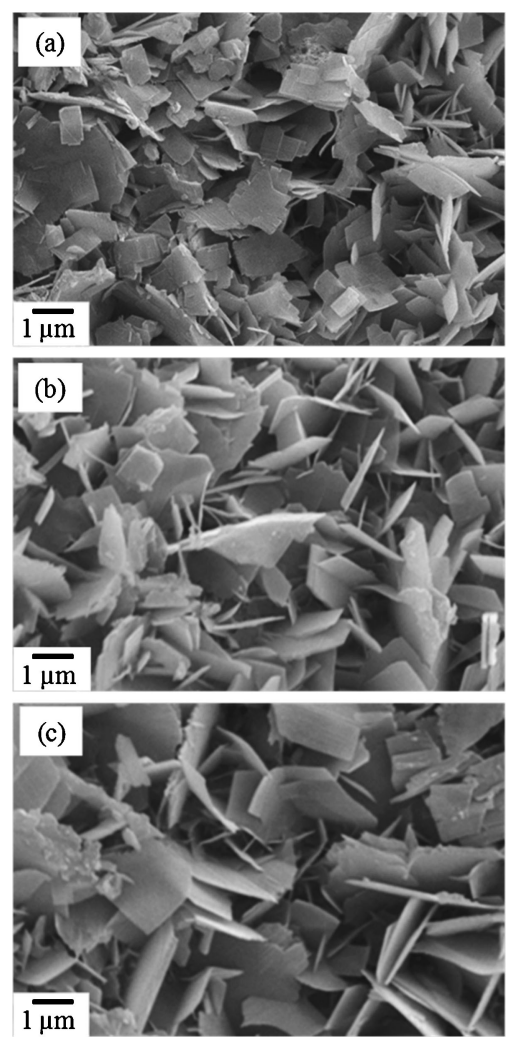

Fig. 3 SEM images of the samples treated in molten salt mixture of $\mathrm{KNO}_{3}$ and $\mathrm{K}_{2} \mathrm{CO}_{3}$ for (a) $\mathrm{K}-873$, (b) $\mathrm{K}-973$, and (c) $\mathrm{K}-1073$.

Table 1 に大気酸化を施した試料 $(\mathrm{H}-873, \mathrm{H}-973$ ，および $\mathrm{H}-1073)$ とそれらに混合溶融塩処理を施した試料 $(\mathrm{K}-873$, K-973 および K-1073)の EDS による組成解析結果を示す. 
大気酸化を施した試料については，大気酸化温度が低い $\mathrm{H}-$ 873 に比較して，H-973 および H-1073 などでは Ti と O の 組成比がほぼ $1: 2$ になっていることから $\mathrm{TiO}_{2}$ が生成した ことがわかる. 一方, 溶融塩処理を施した試料には $\mathrm{K}$ が原 子比で約 5〜 6\%含まれている. なお，原子半径を考えた場 合, $\mathrm{K}$ は $\mathrm{TiO}_{2}$ にドーピングせずに $\mathrm{TiO}_{2}$ の表面に結合し， 薄板状になるという報告から，このナノ板状の生成物は $\mathrm{TiO}_{2}$ と $\mathrm{K}$ の反応により生成したものと推察される15,19).

Fig. 4 に大気酸化によって $\mathrm{TiO}_{2}$ 薄膜を生成させた試料 (H-873, H-973， および H-1073）とそれらに混合溶融塩処 理を施した試料 $(\mathrm{K}-873, \mathrm{~K}-973$ および $\mathrm{K}-1073)$ の $\mathrm{X}$ 線回折 パターンを示す。大気酸化の温度が低い $\mathrm{H}-873$ および $\mathrm{H}-$ 973 では主に $\mathrm{Ti}_{2} \mathrm{O}$ のピークが現れたが，大気酸化温度が高 くなるにつれて $\mathrm{Ti}_{2} \mathrm{O}$ のピークは弱くなり，ルチルのピーク が高くなった。 また, 大気酸化の後に溶融塩処理を施した試 料については大気酸化を施した試料と比較して回折パターン に明確な変化は見られず，Fig. 3 から現れたナノ板状の生成 物を示唆するピークは見られなかった，このことから，溶融 塩処理によって生成したナノ板状の生成物はアモルファスで

Table 1 Elemental composition of $\mathrm{TiO}_{2}$ thin films $(\mathrm{H}-873, \mathrm{H}-$ 973, and $\mathrm{H}-1073$ ) and samples treated in molten salt mixture of $\mathrm{KNO}_{3}$ and $\mathrm{K}_{2} \mathrm{CO}_{3}$ for $20 \mathrm{~h}(\mathrm{~K}-873, \mathrm{~K}-973$, and $\mathrm{K}-1073)$.

\begin{tabular}{cccc}
\hline Element (at\%) & $\mathrm{Ti}$ & $\mathrm{O}$ & $\mathrm{K}$ \\
\hline $\mathrm{H}-873$ & 42.1 & 57.9 & - \\
\hline $\mathrm{H}-973$ & 32.4 & 67.6 & - \\
\hline $\mathrm{H}-1073$ & 33.2 & 66.8 & - \\
\hline $\mathrm{K}-873$ & 28.6 & 66.5 & 4.9 \\
\hline $\mathrm{K}-973$ & 30.8 & 63.9 & 5.3 \\
\hline $\mathrm{K}-1073$ & 31.8 & 65.9 & 5.9 \\
\hline
\end{tabular}

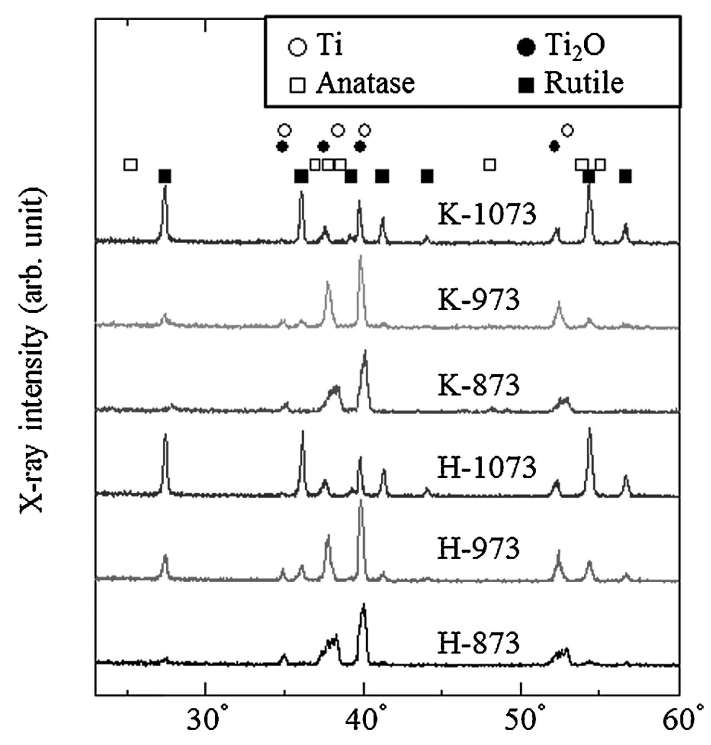

Diffraction angle, $2 \theta$

Fig. 4 X-ray diffraction patterns of the $\mathrm{TiO}_{2}$ thin film $(\mathrm{H}-$ 873, $\mathrm{H}-973$, and $\mathrm{H}-1073)$ and the samples treated in molten mixture of $\mathrm{KNO}_{3}$ and $\mathrm{K}_{2} \mathrm{CO}_{3}$ for $20 \mathrm{~h}(\mathrm{~K}-873, \mathrm{~K}-973$, and $\mathrm{K}-$ 1073).
あることが考えられる。

\section{2 大気酸化を施したチタン酸カリウム}

Fig. 5 に $\mathrm{TiO}_{2}$ 薄膜に溶融塩処理を施した試料 $(\mathrm{K}-873, \mathrm{~K}-$ 973 および $\mathrm{K}-1073)$ に再び大気酸化を施した試料 $(\mathrm{KH}-873$, KH-973 および KH-1073)の試料表面の SEM 像を示す。い ずれの試料においても溶融塩処理後に現れたナノ板状の生成 物からナノ針状の生成物が現れており，特に KH-873 およ び KH-973 に顕著に見られた。

Table 2 にED による KH-873, KH-973 および KH1073 の組成の解析結果を示す. KH-873 と KH-973 につい ては溶融塩処理後の大気酸化により $\mathrm{K}$ の量が溶融塩処理の みを施した試料に比べ, 約 2 倍になっている.これには, Fig. 5 で見られたナノ針状の生成物の量が影響すると考えら れる. ナノ板状の生成物からナノ針状の生成物が成長するこ とで, 表面近くにチタン酸カリウムが現れることで, Kの 量が増加したことが考えられる.

Fig. 6 に溶融塩処理した試料に再び大気酸化を施した試料
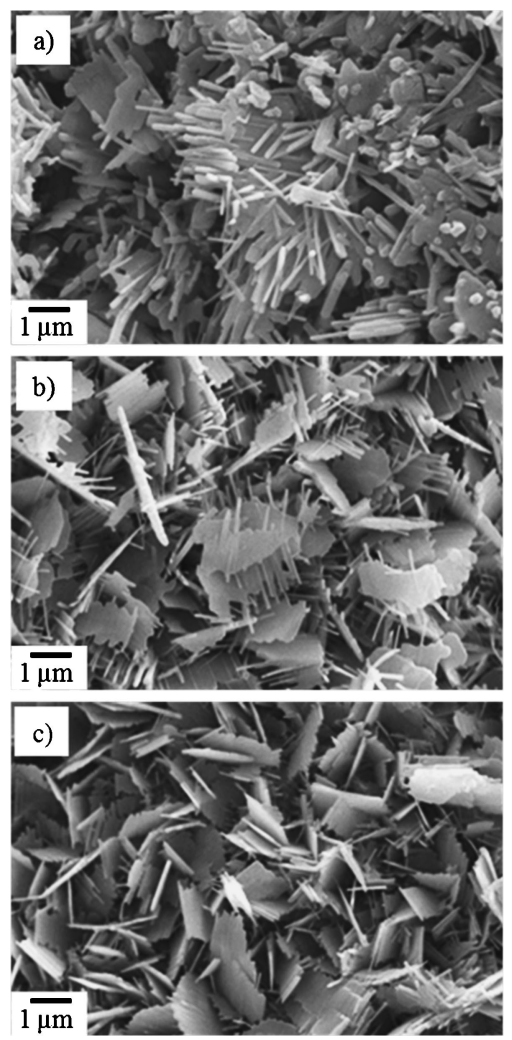

Fig. 5 SEM images of the samples treated in molten salt mixture of $\mathrm{KNO}_{3}$ and $\mathrm{K}_{2} \mathrm{CO}_{3}$ for $20 \mathrm{~h}$ and subsequent oxidation ((a) $\mathrm{KH}-873$, (b) $\mathrm{KH}-973$, and (c) $\mathrm{KH}-1073$ ).

Table 2 Elemental composition of the samples treated in molten salt mixture of $\mathrm{KNO}_{3}$ and $\mathrm{K}_{2} \mathrm{CO}_{3}$ for $20 \mathrm{~h}$ and subsequent oxidation (KH-873, KH-973, and $\mathrm{KH}-1073)$.

\begin{tabular}{cccc}
\hline Element(at\%) & $\mathrm{Ti}$ & $\mathrm{O}$ & $\mathrm{K}$ \\
\hline $\mathrm{KH}-873$ & 24.4 & 65.1 & 10.5 \\
\hline $\mathrm{KH}-973$ & 26.5 & 63.1 & 10.4 \\
\hline $\mathrm{KH}-1073$ & 28.4 & 65.7 & 5.9 \\
\hline
\end{tabular}




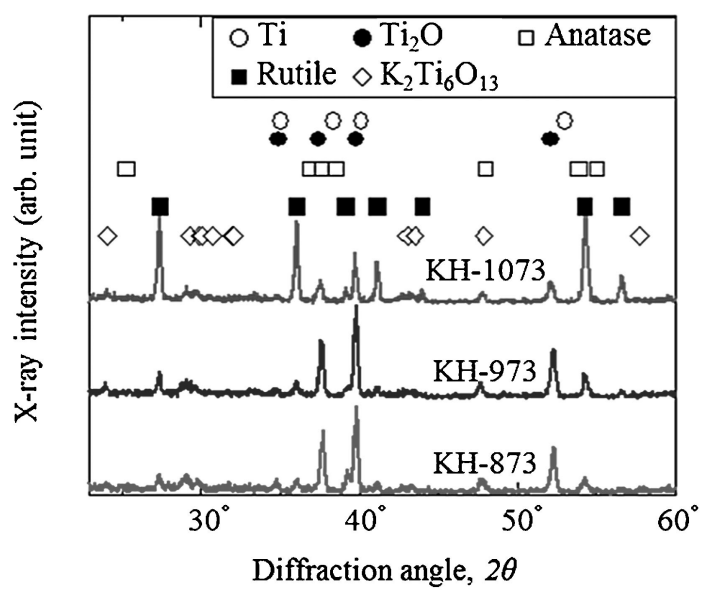

Fig. 6 X-ray diffraction patterns of the samples treated in molten mixture of $\mathrm{KNO}_{3}$ and $\mathrm{K}_{2} \mathrm{CO}_{3}$ for $20 \mathrm{~h}$ and subsequent oxidation ( $\mathrm{KH}-873$, $\mathrm{KH}-973$, and $\mathrm{KH}-1073)$.

(KH-873, KH-973 および $\mathrm{KH}-1073)$ の X 線回折パターン を示す。ナノ針状の生成物が多く現れた KH-873 および $\mathrm{KH}-973$ では $\mathrm{K}_{2} \mathrm{Ti}_{6} \mathrm{O}_{13}$ のピークが現れている.これは大気 酸化した後に溶融塩処理を施した試料 $(\mathrm{K}-873, \mathrm{~K}-973$ およ び $\mathrm{K}-1073)$ には現れていなかったピークである. $\mathrm{TiO}_{2}$ 薄膜 に対し溶融塩処理を施した試料では Fig. 3 に示したナノ板 状のアモルファスのナノ生成物が現れていたが，このアモル ファスの生成物に対し大気酸化を施すことでそれらが結晶化 し， $\mathrm{K}_{2} \mathrm{Ti}_{6} \mathrm{O}_{13}$ になったと考えられる20). なお， $\mathrm{KH}-1073$ に おいては $\mathrm{K}_{2} \mathrm{Ti}_{6} \mathrm{O}_{13}$ のピークはほぼ見られなかったことから， $\mathrm{TiO}_{2}$ と $\mathrm{K}$ の反応によって生成したナノ板状の生成物が結晶 化して $\mathrm{K}_{2} \mathrm{Ti}_{6} \mathrm{O}_{13}$ になる条件は $\mathrm{TiO}_{2}$ 薄膜の結晶相の状態に 依存することが明らかになった。すなわちルチルの $\mathrm{TiO}_{2}$ 薄 膜と $\mathrm{K}$ との反応では， $\mathrm{K}_{2} \mathrm{Ti}_{6} \mathrm{O}_{13}$ には生成しにくいこと，お よび $\mathrm{Ti}_{2} \mathrm{O}$ と $\mathrm{K}$ の反応によって生成したナノ板状の生成物は $\mathrm{K}_{2} \mathrm{Ti}_{6} \mathrm{O}_{13}$ に結晶化しやすいことが考えられる.

\section{3 光触媒機能}

Fig. 7 に溶融塩処理した試料に再び大気酸化を施した試料 (KH-873, KH-973 および KH-1073)への紫外光照射による メチレンブルー水溶液の濃度変化曲線を示す. また, メチレ ンブルーの濃度-照射時間曲線から最小二乗法を用いて照射 時間 $20 \mathrm{~min}$ から $3 \mathrm{~h}$ までの勾配を算出した分解活性指数 $R$ を Fig. 8 に示す. 各試料ともメチレンブルーの濃度の低下 が見られることから光触媒機能を有しており, 中でも KH873 は分解活性指数 $R=13.5$ と高い光触媒機能を示した.

KH-873 および KH-973 が KH-1073 に対し高い光触媒機能 を有している要因としては, 高い光触媒機能を有する $\mathrm{K}_{2} \mathrm{Ti}_{6} \mathrm{O}_{13}$ の生成量が多いこと, 抽よ゙それによる表面積の 増大によるものと考えられる。

\section{4. 結言}

本研究では，メカニカルコーティング法により成膜した $\mathrm{Ti}$ 薄膜に $\mathrm{KNO}_{3}$ と $\mathrm{K}_{2} \mathrm{CO}_{3}$ の混合溶融塩処理をすることで,

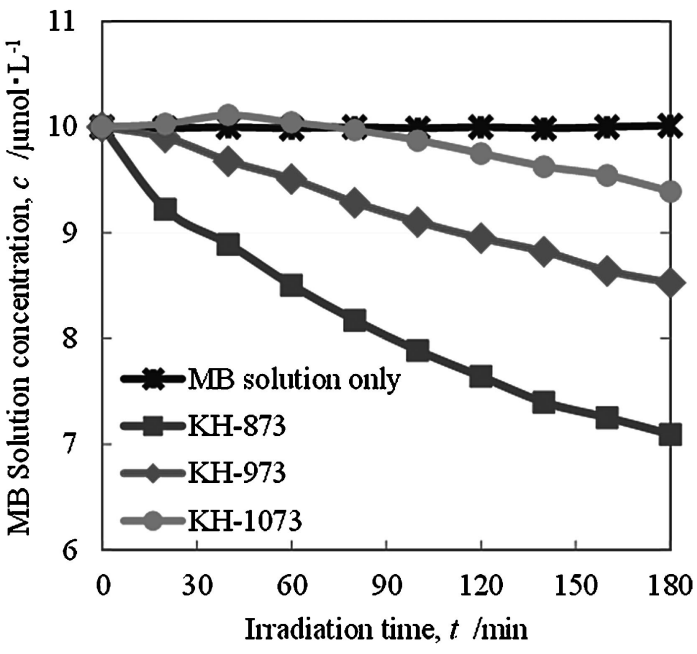

Fig. 7 Photocatalytic degradation of methylene blue under UV irradiation by the samples treated in molten salt mixture of $\mathrm{KNO}_{3}$ and $\mathrm{K}_{2} \mathrm{CO}_{3}$ for $20 \mathrm{~h}$ and subsequent oxidation ( $\mathrm{KH}-873$, $\mathrm{KH}-973$, and $\mathrm{KH}-1073)$.

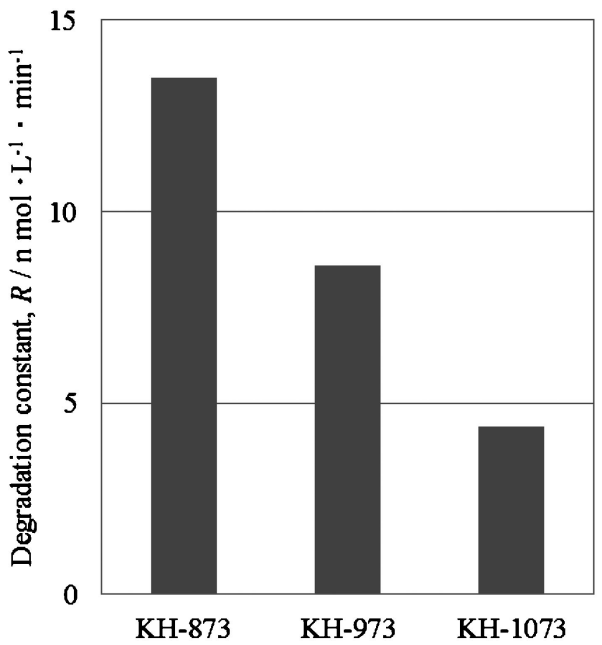

Fig. 8 Degradation constant of the samples treated in molten salt mixture of $\mathrm{KNO}_{3}$ and $\mathrm{K}_{2} \mathrm{CO}_{3}$ for $20 \mathrm{~h}$ and subsequent oxidation (KH-873, KH-973, and $\mathrm{KH}-1073)$.

ナノ板状のアモルファスのチタン酸カリウムを作製した．さ らにアモルファスのチタン酸カリウムに対して大気酸化を施 すことでナノ針状の生成物を作製した．作製した試料につい ては組織と組成の解析, および光触媒機能の評価を行った. その結果, 以下のことを明らかにした。

(1) $\mathrm{KNO}_{3}$ と $\mathrm{K}_{2} \mathrm{CO}_{3}$ の混合溶融塩処理により, ナノ構造 を有する光触媒薄膜を作製するプロセスを確立した。

(2) $\mathrm{TiO}_{2}$ 薄膜に $\mathrm{KNO}_{3}$ と $\mathrm{K}_{2} \mathrm{CO}_{3}$ の混合溶融塩処理を施す ことにより, ナノ板状のアモルファスのチタン酸カリウムが 生成し, それらを大気酸化させることでナノサイズの針状 $\mathrm{K}_{2} \mathrm{Ti}_{6} \mathrm{O}_{13}$ が生成した。 また作製したナノサイズの針状 $\mathrm{K}_{2} \mathrm{Ti}_{6} \mathrm{O}_{13}$ は高い光触媒機能を発現した.

文献

1) A. Fujishima and K. Honda: Nature 238(1972) 37-38. 
2) H. Yahoubi, N. Taghavinia and E. K. Alamdari: Surf. Coat. Technol. 204(2010) 1562-1568.

3) K. Nakata and A. Fujishima: J. Photochem. Photobiol. C 13 (2012) 169-189.

4) O. Akhavan and E. Ghaderi: Surf. Coat. Technol. 204(2010) 3676-3683.

5) Z. Chen and K. Zhou: Surf. Coat. Technol. 263(2015) 61-65.

6) G. Wang, H. Wang, Y. Ling, Y. Tang, X. Yang, R. Fitzmoris, C. Wang, J. Zhang and Y. Li: Nano. Lett. 11 (2011) 3026-3033.

7) F. Amano, T. Yasumoto, T. Shibayama, S. Uchida and B. Ohtani: Appl. Catal. B 89(2009) 583-589.

8) N. Bao, L. Shen and K. Yanagisawa: J. Phys. Chem. B 108 (2004) 16739-16745.

9) S. Tawkaew, M. Chareonpanich and S. Supothina: Mater. Chem. Phys. 111 (2008) 232-237.

10) Y. Bessekhouad, D. Robert, J. $-\mathrm{V}$. Weber and N. Chaoui: J. Photochem. Photobiol. A: Chem. 167 (2004) 49-57.

11) T. Docters, J. M. Chovelon, J. M. Herrmann and J. P. Deloume: Applied Catalysis B: Environmental 50(2004) 219-226.
12) Y. Z. Shen, K. H. Oh and D. N. Lee: Scr. Mater. 53(2005) 13451349.

13) Y. Ito and T. Goto: Youyunen-no-ouyou, (Aipishi, Tokyo, 2003) pp. 199-217.

14) Y. Ito and T. Takenaka: Youyunen-no-kagaku, (Aipishi, Tokyo, 2005) pp. 284-285.

15) A. V. Gorokhovsky, J. I. Escalante-Garcia, T. SanchezMonjaras and C. A. Gutierrez-Chavarria: J. Eur. Cera. Soc. 24 (2004) 3541-3546.

16) Y. Hirakawa, Y. Lu, H. Yoshida, K. Matsuzaka, L. Hao and H. Sato: J. Japan. Inst. Met. Mater. 77 (2013) 287-293.

17) H. Yoshida, Y. Lu, H. Nakayama and M. Hirohashi: J. Soc. Mater. Sci., Japan 46(2009) 141-146.

18) Y. Lu, L. Hao, K. Toh and H. Yoshida: Advanced Materials Research 415-417 (2012) 1942-1948.

19) C. Liu, X. H. Lu, G. Yu, X. Feng, Q. T. Zhang and Z. Z. Xu: Mater. Chem. Phys. 94(2005) 401-407.

20) G. Du, Q. Chen, P. Han, Y. Yu and L. Peng: Phys. Rev. 67 (2003) 035323-1-7. 